\title{
INTER-FIRM KNOWLEDGE SHARING EFFECTIVENESS: AN EMPIRICAL EXAMINATION OF
} ADAPTATION AMBIDEXTERITY

\author{
Binh H. Nguyen, New York Institute of Technology - Vancouver, Canada \\ Gary L. Frankwick, University of Texas at El Paso, USA \\ Karen E. Flaherty, Oklahoma State University, USA
}

\begin{abstract}
As more firms outsource non-core operational functions and as they create alliances to develop new products, inter-firm knowledge sharing (IKS) based on relationship-specific adaptation (RSA) becomes more and more important. Employing ambidexterity and learning theory, this study surveyed 108 managers of high-tech firms to determine if ambidexterity helps RSA improve IKS. Moderated regression results show positive effects of adaptation balance, negative effects of adaption integration, and positive moderation of relational norms on balance and positive effects of loose coupling of the system.

References available upon request.
\end{abstract}

